\title{
ESTUDOS INICIAIS PARA ENSAIOS E CONSTRUÇÃO DE CÚPULAS GEODÉSICAS USANDO COLMOS DE BAMBU
}

INITIAL STUDIES FOR TESTS AND CONSTRUCTION OF GEODESIC DOMES USING BAMBOO CULMS

Fabiano Ostapiv, Dr. (UTFPR)

Celso Salamon, Dr. (UTFPR)

Joamilton Stahlschmidt, M.Sc. (UFFPB)

Celso Ferraz Bett, M.Sc. (UFFPB)

\section{Palavras Chave}

Cúpulas Geodésicas; Bambu; Ensaios; Construção

\section{Key Words}

Geodesic Domes; Bamboo; Essay; Construction;

\section{RESUMO}

O trabalho mostra o procedimento para a construção de um domo geodésico de $4 \mathrm{~m}$ de diâmetro e 1,8m de altura usando segmentos de 1,2m de colmos de bambu tuldóides, usando a técnica de amarração. Também mostra a construção e ensaio de carregamento de duas maquetes de domos, ambas com a mesma geometria e massas semelhantes, porém de materiais diferentes. Uma maquete foi feita com barras de bambu mossô (Phyllostachys pubescens) de $3 \mathrm{~mm}$ de diâmetro e a outra com barras de aço baixo carbono com 1mm de diâmetro. Na confecção das maquetes foram mostrados aspectos de otimização da construção em relação ao domo de bambu tuldóides, como a utilização de elementos de duas barras. No ensaio de carregamento estático das maquetes foi evidenciado, através de fotografias e medições de deslocamento da estrutura, o comportamento mecânico superior da estrutura de bambu em relação à estrutura de aço. Enquanto o domo de bambu resistiu a 38 vezes o seu peso próprio, apresentando um deslocamento pontual de 3,2cm, o domo de aço resistiu apenas 0,86 do seu peso próprio apresentando a mesma deformação.

\section{ABSTRACT}

The work shows the procedure for the construction of a geodesic dome of $4 \mathrm{~m}$ in diameter and $1.8 \mathrm{~m}$ in height using segments of $1.2 \mathrm{~m}$ of culms of bamboo tuldoides, using the mooring technique. Also shows the construction and test of loading two models of domes, both with the same geometry and near mass, but of different materials. A mock-up was made with mosso bamboo bars (Phyllostachys pubescens) of $3 \mathrm{~mm}$ in diameter and the other with bars of low carbon steel with $1 \mathrm{~mm}$ of diameter. In the construction of the models, aspects of optimization of the construction were shown in relation to the bamboo dome tuldóides, as the use of elements of two bars. In the test of the models was evidenced, through photographic elements and measures of displacement of the structure, the very superior behavior of the bamboo structure in relation to the steel structure. While the bamboo dome resisted 38 times its own weight, presenting a point displacement of $3.2 \mathrm{~cm}$, the steel dome resisted only 0.86 of its own weight presenting the same deformation. 


\section{INTRODUÇÃO}

O bambu é uma planta muito usada na construção de casas, pontes e estruturas diversas. Leve, resistente, bonito e tradicional, estas são algumas características que fazem do bambu um bom material para ser usado na construção civil. As comunidades tradicionais usam bambu para construção de habitações a milhares de anos e seu comportamento é bem conhecido, Ostapiv (2017).

Uma cúpula, ou domo geodésico é uma estrutura arquitetônica formada por triângulos ou outras formas geométricas regulares que compõem uma superfície inscrita em uma semiesfera. Usado popularmente na construção de habitações ou para cobrir grandes espaços desde a antiguidade. $O$ domo destaca-se por não possuir colunas de sustentação, ser de fácil montagem, muito leve e estável. É considerada uma das estruturas mais resistentes por quantidade de material já inventada, a sua estrutura consiste em barras de qualquer material, e o domo pode ser feito em qualquer dimensão, desde que o tamanho das suas barras e o número de formas geométricas que compõe a superfície da estrutura sejam calculados corretamente. O uso do bambu para construção de domos ou cúpulas é um uso clássico deste material.

O principal objetivo deste trabalho é mostrar como fazer uma cúpula geodésica usando colmos de bambu amarrados, apresentando a construção de forma didática para que a mesma possa ser reproduzida facilmente, através da montagem passo a passo. Além disso, construir maquetes e realizar ensaios de carregamento hidráulico para mostrar a boa resistência mecânica da estrutura de bambu e comparar seu comportamento com uma estrutura de aço com a mesma massa e dimensão final.

\section{O DOMO GEODÉSICO}

O domo geodésico montado neste trabalho é similar a estrutura dos gomos geométricos de uma bola de futebol, composta por hexágonos e pentágonos, como mostrado na Figura 01. Esta estrutura é um poliedro de Arquimedes chamado icosaedro truncado. Bicalho, (2013).

Figura 01: Nas arestas dos gomos de uma bola de futebol, visualiza-se um domo geodésico.

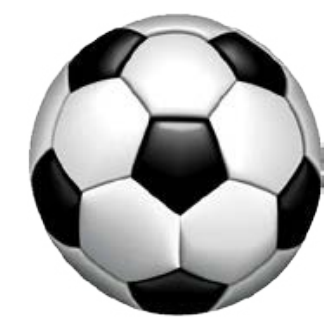

Fonte: Bicalho, 2013
As arestas dos hexágonos e dos pentágonos são todas iguais, por isso todos os segmentos de colmo de bambu têm todos o mesmo comprimento. No entanto, como a cúpula é uma calota esférica, no terceiro e último nível haverá 5 meios hexágonos e o comprimento desta aresta de fechamento será maior.

\section{CONSTRUÇÃO DE UM DOMO USANDO COLMOS DE BAMBU TULDOIDES DE 1,2m}

Podem ser usados colmos de diferentes espécies de bambu com variados diâmetros e comprimentos. Neste trabalho, para a construção de um domo geodésico foi utilizado um bambu entouceirante de porte médio da espécie Bambusa tuldoides, pois os colmos são resistentes, apresentam parede grossa e diâmetro médio na base de $6 \mathrm{~cm}$, são razoavelmente lineares, pouco suscetíveis ao ataque de insetos, bastante usados para construções e estruturas no dia a dia. Além disso, ocorrem em todo o Brasil onde são encontrados com facilidade e em boa quantidade. Segundo Nascimento e colaboradores (2002), a espécie apresenta valores de resistência à compressão paralela às fibras variando de 65,8 a 88,2 MPa, e de resistência ao cisalhamento de 11,5 a 15,8 Mpa.

Todos os segmentos de colmos de bambu foram cortados com 1,2m de comprimento. A estrutura analisada neste trabalho, foi realizada no Instituto Federal do Paraná, Campus Coronel Vivida (IFPR-CV) em junho de 2007, com alunos e professores da instituição.

\subsection{As tiras de borracha}

As tiras de borracha utilizadas na amarração dos bambus, foram provenientes de câmaras de pneus de caminhão descartadas. Este material é obtido em borracharias e foi usado na produção das tiras para amarração, obtidas com o uso de tesouras comuns como mostrado na Figura 02. Uma vantagem no uso deste material é que os pontos de amarração ficam sempre tensionados e mantém a rigidez da estrutura.

Figura 02: Produção de tiras de borracha de câmaras de pneu de caminhão para amarração.

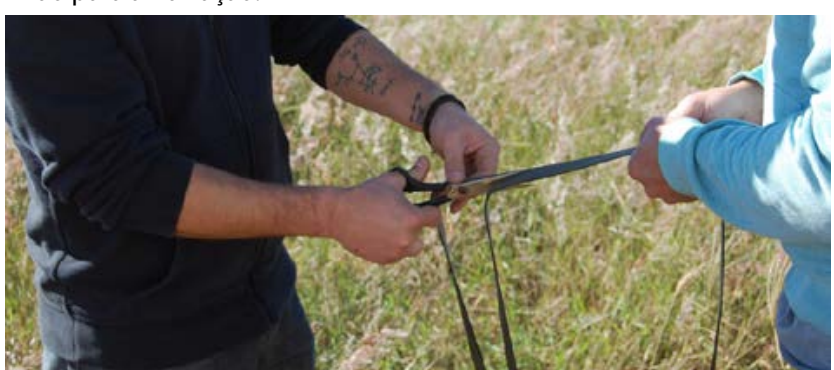




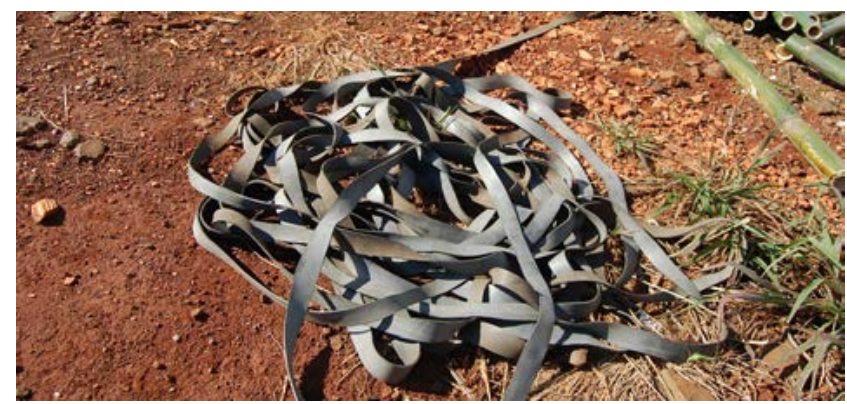

Fonte: Ostapiv

Segundo o CTB, a borracha butílica é um copolímero de isobutileno (98\%) e de isopreno (2\%), utilizada na fabricação de câmaras de ar para automóveis e caminhões, cujas principais características são:

- Elevada impermeabilidade aos gases e ao ar;

- Boas propriedades de flexão;

- Elevado amortecimento;

- Boa resistência ao calor;

- Boa resistência ao envelhecimento provocado pela intempérie e pelo ozônio;

Apresenta densidade de 0,92 g/cm3, tensão de ruptura entre 7 e $17 \mathrm{MPa}$ com alongamento de até $800 \%$ antes de romper, apresentando vida útil entre 5 e 10 anos desde que não fique exposta a intempéries, luz solar e ultravioleta.

\subsection{Seleção dos colmos para produção das pe- ças de bambu que serão usadas no domo}

Os colmos colhidos devem ser maduros, ou seja, devem ter 3 ou mais anos de idade. Não devem ser tortos e tampouco apresentarem falhas como furos, trincas e ataques de insetos. Caso seja possível, fazer um tratamento com preservantes. As pontas dos segmentos de bambu podem ser lixadas para melhorar o acabamento. Outra possibilidade para melhorar o acabamento final da estrutura é tratar os colmos com fogo usando um maçarico.

O ideal é trabalhar com os segmentos de colmos de bambu secos, ou seja, com teor de umidade baixo, entre 12 a $15 \%$ é o ideal, pois se forem recém cortados, os colmos terão muita água e um peso muito maior, o que atrapalha as etapas construtivas, especialmente as últimas. Os colmos verdes podem ter mais do que o dobro do peso dos colmos secos, além disso, ao secar o bambu encolhe, diminuindo o seu diâmetro. Se por exemplo, for utilizado bambu verde com elemento de amarração tipo corda ou arame, após secar os colmos, a estrutura perde rigidez, os colmos podem ficar soltos e a geodésica bamba.
Figura 03: Segmentos de colmos de bambu tuldoides selecionados para serem usados na estrutura geodésica.
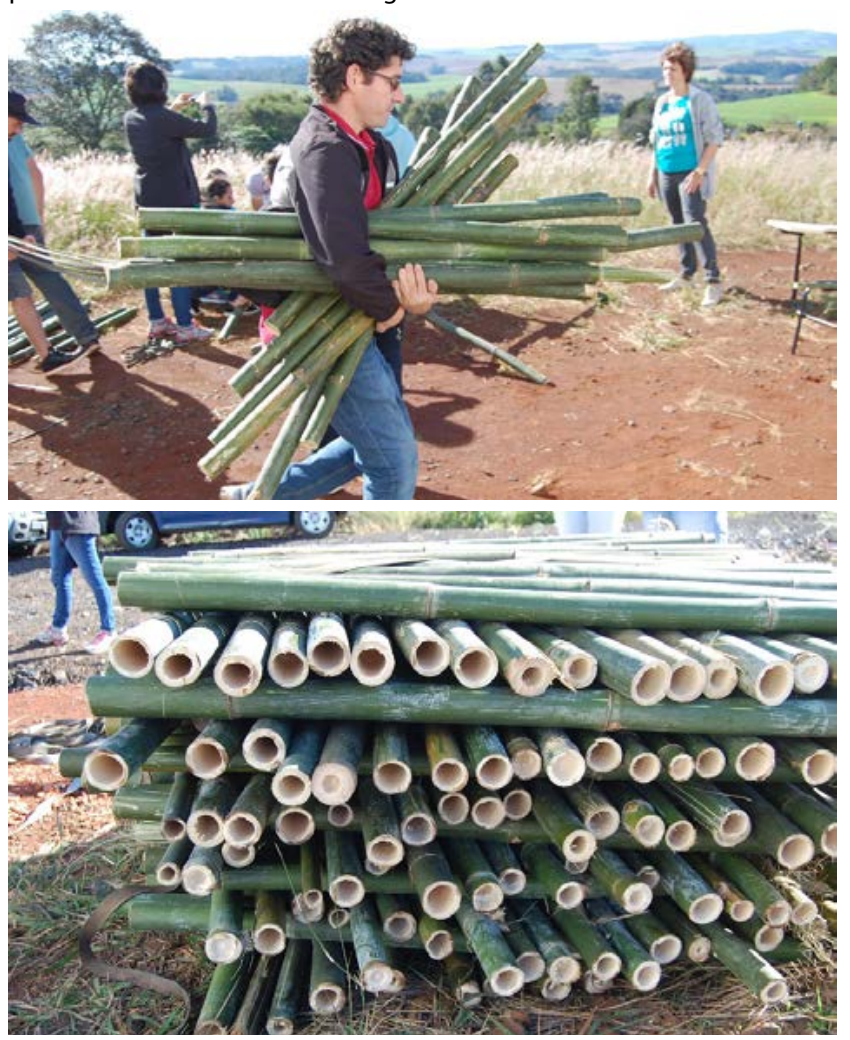

Fonte: Ostapiv

\subsection{Triângulo básico para amarração dos colmos}

Para permitir a união amarrada dos colmos de bambu, em todos os vértices dos hexágonos e pentágonos haverá um triângulo básico. Serão necessários construir 20 destes triângulos para fechar a estrutura e todos eles deverão ter a mesma orientação espacial e tamanho, como mostrado na Figura 04.

O triângulo formado deve ser equilátero e as pontas dos colmos que excedem o triângulo devem ter a mesma medida. Para isso deve-se usar uma régua ou um gabarito para garantir que as arestas do triângulo tenham todas 0 mesmo comprimento. Este arranjo deve ser mantido na estrutura toda.

Figura 04: Disposição inicial do elemento triangular básico e amarração do triângulo com tiras de borracha.

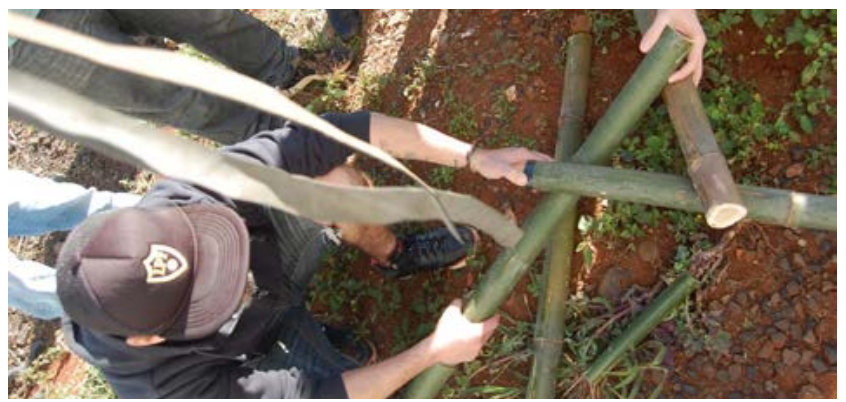




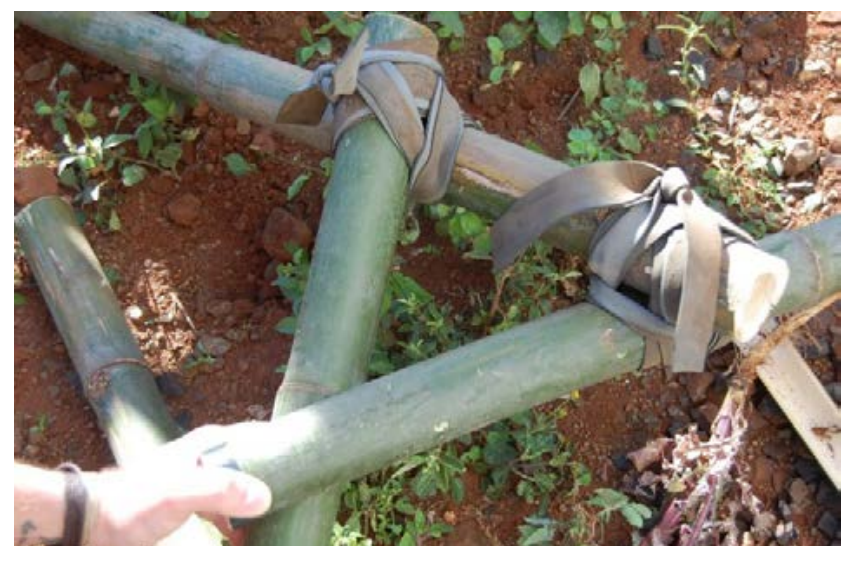

Fonte: Ostapiv

A amarração dos colmos pode ser feita de várias maneiras, o uso de tiras de borracha é interessante pois o comportamento elástico da tira permite o uso de colmos recém colhidos e uma maior tensão de tração na amarração. A maior desvantagem desta solução é a baixa vida útil da amarração se a mesma ficar sujeita a insolação direta, pois desta forma a borracha vai degradar, principalmente pela ação dos raios ultravioletas, ressecando e rompendo. Para aumentar a vida útil da amarração a mesma pode ser revestida com algum tipo de cobertura reflexiva.

Figura 05: Elemento estrutural triangular inicial suportando carga concentrada no centro da estrutura.

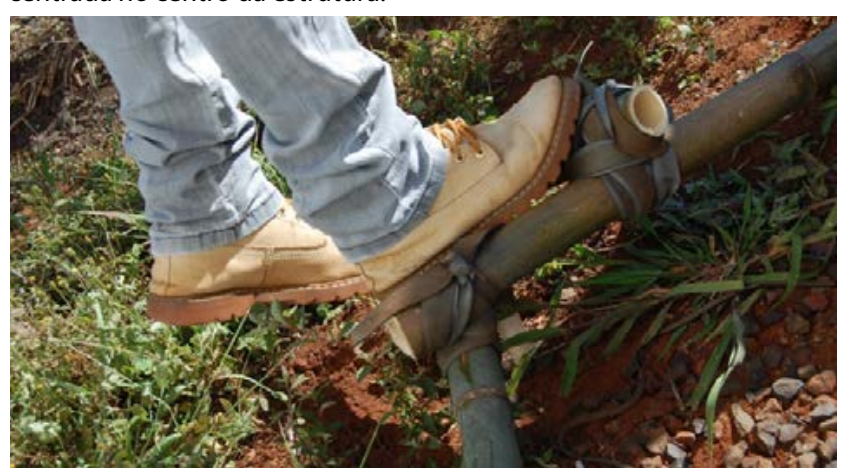

Fonte: Ostapiv

Os colmos dispostos desta forma se auto apoiam uns sobre os outros, sustentando cargas de compressão que se distribuem na estrutura, como mostrado na Figura 05. Nesta primeira fase a altura do elemento amarrado ao solo é de aproximadamente $20 \mathrm{~cm}$.

\subsection{Montagem do domo geométrico com 3 níveis}

A partir do primeiro triângulo amarrado, vão sendo medidos e dispostos em sequência, outros triângulos básicos que vão sendo então incorporados e amarrados na estrutura inicial. Nesta etapa foi construído um hexágono regular com aresta de $90 \mathrm{~cm}$ no centro da estrutura.
Figura 06: Amarração do topo da geodésica, construção de um hexágono de lado $90 \mathrm{~cm}$.

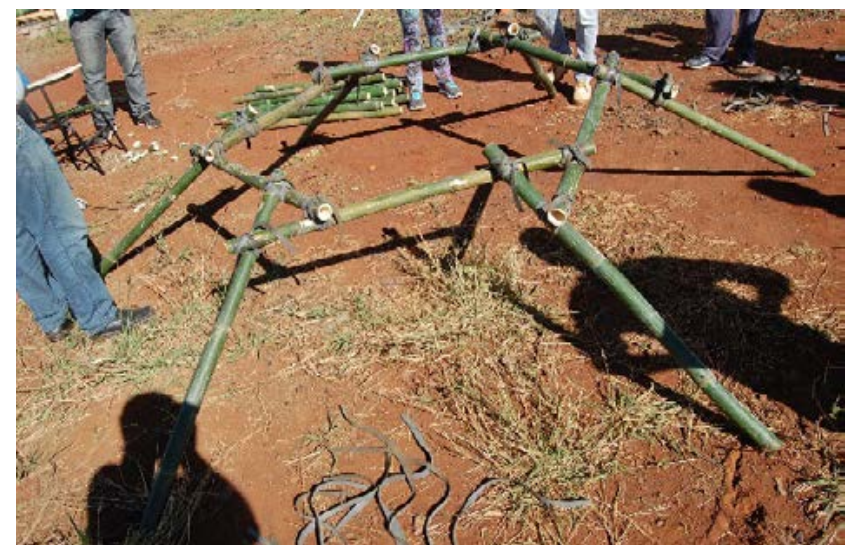

Fonte: Ostapiv

Nesta etapa foram amarrados 6 triângulos e a altura parcial do domo é de aproximadamente $50 \mathrm{~cm}$. A partir deste hexágono central, uma nova etapa de amarração de 6 triângulos foi feita, chegando ao terceiro nível da estrutura, mostrado na Figura 07. Na amarração dos colmos continua-se a manter o arranjo e a orientação inicial do triângulo básico, mostrado na Figura 04.

Figura 07: Segundo e terceiro nível da estrutura, construção de pentágonos e hexágonos regulares.
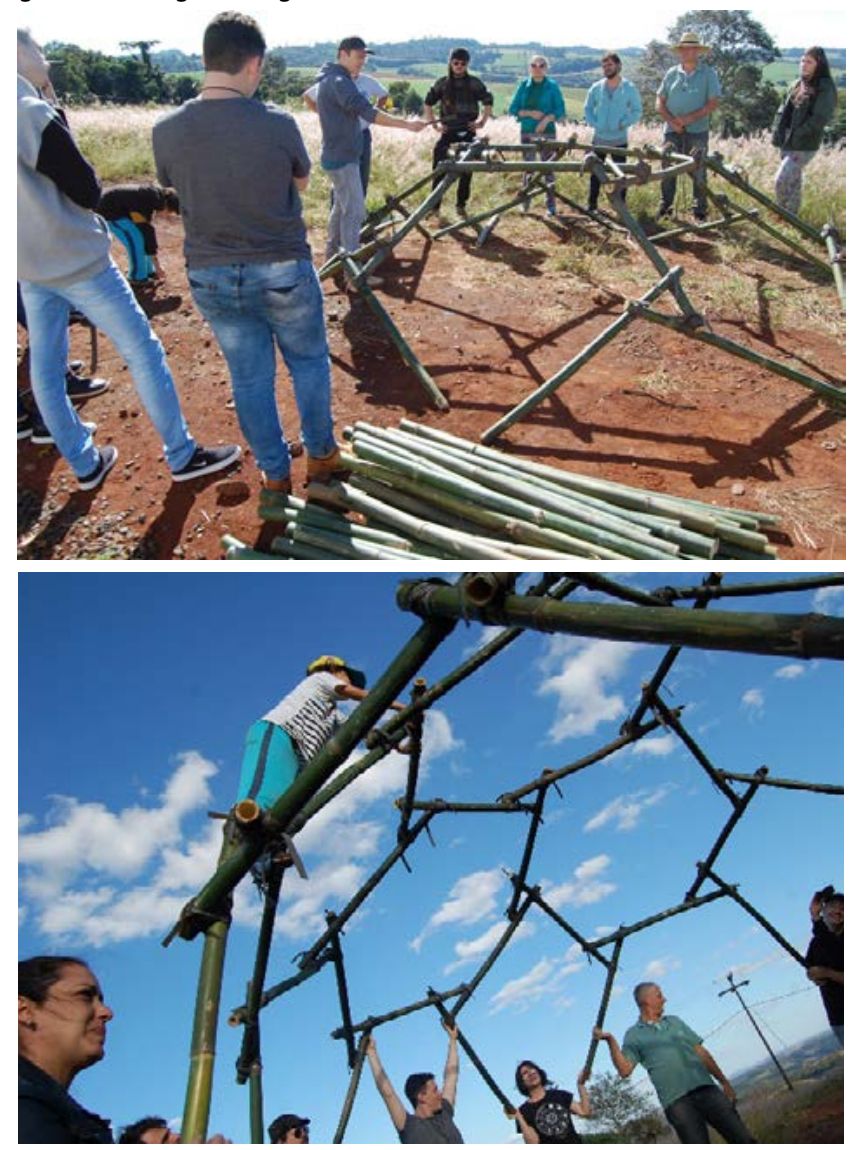

Fonte: Ostapiv 
Fazendo o fechamento do terceiro nível com mais 12 triângulos básicos, são obtidos então 5 novos hexágonos regulares e um pentágono. Nesta etapa então a altura total do domo geodésico foi de aproximadamente, 1,8m e o seu diâmetro $4 \mathrm{~m}$.

O fechamento da cúpula geodésica pode ser feito em diferentes etapas unindo as pontas soltas dos segmentos de colmo da estrutura com novos segmentos que ficarão dispostos horizontalmente ao solo. No terceiro nível a estrutura já está próxima a forma de uma semiesfera. $\mathrm{O}$ domo geodésico obtido pode ser apoiado diretamente no solo, mas também sobre paredes ou colunas, dependendo da aplicação final desejada.

\subsection{Utilização do domo geodésico}

Caso a estrutura seja utilizada para fechar um ambiente qualquer e sobre ela for utilizada uma lona ou um filme plástico como revestimento externo da geodésica, haverá problemas com as pontas dos colmos de bambu nas extremidades dos triângulos. Estas pontas normalmente furam o revestimento devido principalmente à ação do vento. Assim para melhorar a vida útil destes materiais é recomendado fazer um bom acabamento lixado nas extremidades dos colmos para evitar quinas e arestas muito cortantes. Também é possível fazer um revestimento destas pontas com outro tipo de material como: fitas adesivas, tecidos, filmes plásticos, a própria borracha das câmaras de ar entre outros.

Caso seja feito um revestimento interno, estes problemas com as extremidades dos colmos não existirão, pois internamente a estrutura não apresenta pontas. No entanto, outros problemas de revestimento surgirão.

Se a estrutura não for revestida e ficar aberta no meio ambiente, como para o caso de ser usada para suportar o crescimento de plantas em hortas ou jardins, então é importante revestir as amarrações de borracha com fitas reflexivas aluminizadas, para aumentar a vida útil da estrutura. Outras possibilidades de material para amarração como cordas, arames e fibras naturais ou sintéticas, também são possíveis. Uma boa opção é a solução usada na construção das maquetes, fios de nylon reforçado com resina de poliéster.

Estruturas mais rígidas podem ser obtidas usando colmos de bambu amarrados como reforço, ou com o fechamento parcial ou total da estrutura usando painéis de madeira, por exemplo.

\section{CONSTRUÇÃO DE MAQUETES COM VARETAS DE BAMBU MOSSÔ E AÇO}

O projeto, análise e construção de uma maquete pode indicar várias questões importantes que podem ser usadas na construção e projeto de um domo de dimensões maiores. Além de ilustrar o passo a passo construtivo permitindo sua otimização. Além disso, o ensaio de um modelo em escala menor permite prever o comportamento de estruturas maiores. Para Rozestraten (2009), o contato e a visualização da maquete física a tornam um meio de representação que em muito se aproxima da realidade.

O material utilizado na construção das maquetes foram:

- Barras de bambu mossô feitas a partir de espetinhos de bambu obtidas do comércio.

- Barras de aço baixo carbono, cobreado de $1 \mathrm{~mm}$ de diâmetro.

- Fio de nylon para amarração.

- Resina poliéster para revestimento das amarrações.

O bambu mossô é um dos bambus mais utilizados e plantados no mundo, Wang e Huang (1996), muito usado na confecção de inúmeros produtos, entre eles, palitos e espetinhos. Estes últimos, que são facilmente encontrados no mercado brasileiro em diversas dimensões, foram usados na construção da maquete da cúpula geodésica de bambu.

\subsection{Construção de maquetes}

Ao invés de iniciar a estrutura por um hexágono, como o da Figura 06, a construção inicial de um pentágono é mais indicada, por ser mais fácil o entendimento tanto da lógica geométrica como da construtiva, facilitando também a etapa final de fechamento da estrutura.

Nas maquetes as cúpulas geodésicas foram iniciadas por um pentágono regular. Na segunda etapa foram construídos 5 hexágonos regulares e na terceira e última etapa, na qual se obtém uma quase semiesfera, foram acrescentados 5 pentágonos completos e 5 meios hexágonos. Exatamente como a estrutura mostrada na vista superior da bola de futebol da Figura 02.

Os elementos triangulares mostrados na Figura 08 são importantes e se repetem na estrutura, a ordem construtiva do triângulo básico deve ser mantida em toda a estrutura. Já os elementos de 2 barras mostrados na Figura 08, podem ser amarrados separadamente e serem incorporados depois na estrutura da geodésica. Desta forma a montagem da estrutura fica mais rápida e facilitada, pois parte do trabalho de amarração da geodésica e dos elementos de 2 barras podem ser feitos em paralelo. 
Figura 08: Triângulo básico e elementos de 2 barras que se repetem na estrutura
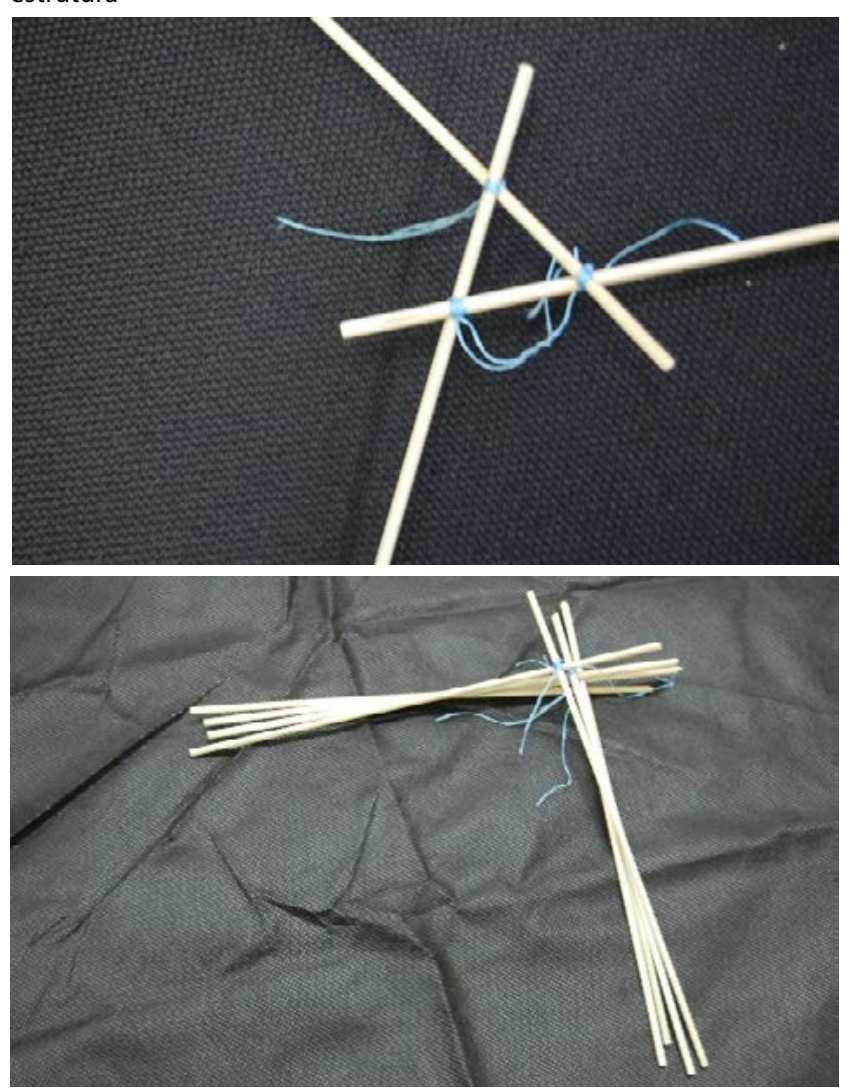

Fonte: Ostapiv

Na Figura 09 é mostrado o pentágono no primeiro nível e a lógica de incorporação dos elementos de 2 barras na estrutura da cúpula geodésica no segundo nível.

Figura 09: Pentágono do primeiro nível e elementos de 2 barras sendo fixados na estrutura
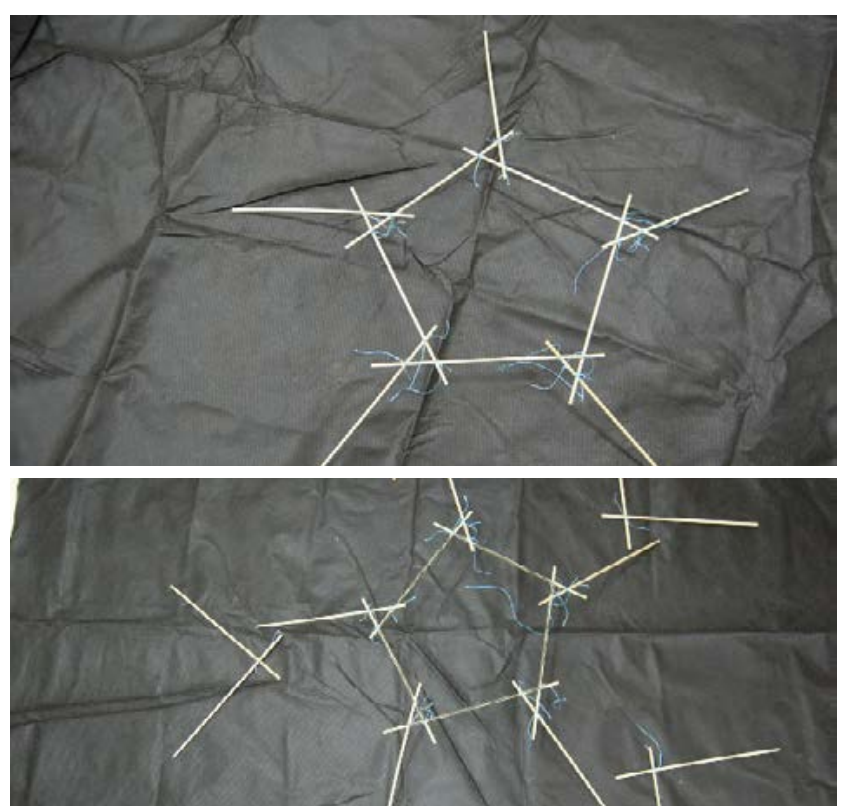

Fonte: Ostapiv
Na Figura 10 é mostrado o segundo nível com 5 hexágonos e o domo geodésico já está montado no terceiro nível. As pontas dos fios de amarração foram aparadas e nos pontos de amarração onde existem os nós, foi feito reforço com resina de poliéster para melhorar a fixação das barras.

Figura 10: Pentágono central e cinco hexágonos no segundo nível e fechamento dos 5 pentágonos e dos 5 meios hexágonos do nível 3
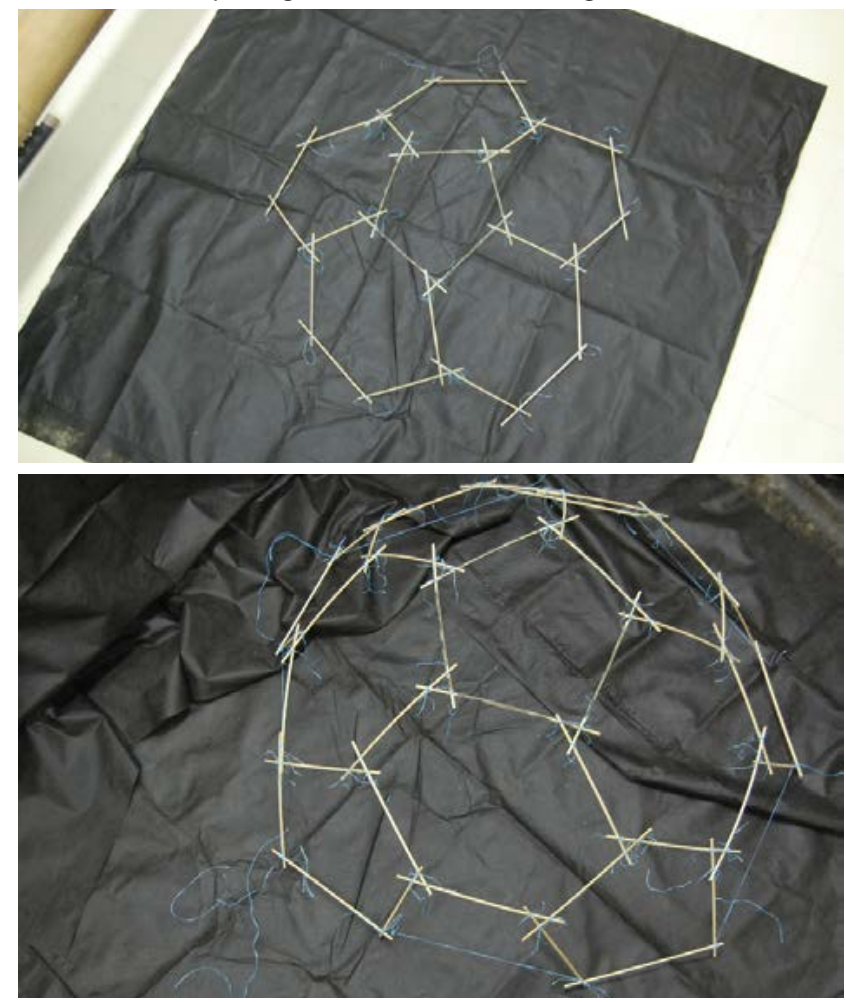

Fonte: Ostapiv

\subsection{Construção de maquetes}

Entre as características mostradas na Tabela 01, destacam-se o grande volume coberto pela estrutura geodésica, de aproximadamente 98 litros. No caso das características do domo feito de bambu, mostradas na Tabela 02, destaca-se a pequena massa total da estrutura, de apenas 63g. Ou seja, o domo construído em varetas de bambu seco, a $15 \%$ de teor de umidade (t.u.) é muito leve.

Tabela 01: Características do domo geodésico de aresta 17,5cm.

\begin{tabular}{|l|c|}
\hline DOMO GEODÉSICO - icosaedro truncado & \\
\hline$n^{\circ}$ de barras $23 \mathrm{~cm}$ & 40 \\
\hline$n^{\circ}$ de nós de amarração na estrutura & 80 \\
\hline$n^{\circ}$ de triângulos & 20 \\
\hline$n^{\circ}$ de pentágonos & 6 \\
\hline$n^{\circ}$ de hexágonos & 5 \\
\hline Comprimento médio das arestas dos poligonos & $17,5 \mathrm{~cm}$ \\
\hline Diâmetro do domo & $80 \mathrm{~cm}$ \\
\hline Altura do domo & $37 \mathrm{~cm}$ \\
\hline Área aproximada da superfície do domo & $1,5 \mathrm{~m}^{2}$ \\
\hline Volume coberto pelo domo & 98 litros \\
\hline
\end{tabular}

Fonte: Elaborado pelos autores 
Tabela 02: Domo feito com barras de bambu mossô diâmetro médio 3mm

\begin{tabular}{|l|c|}
\hline Massa média das barras de bambu mossô (t .u. 15\%) & $1,45 \mathrm{~g}$ \\
\hline Massa total de bambu & $58,4 \mathrm{~g}$ \\
\hline Massa total da estrutura & $63 \mathrm{~g}$ \\
\hline
\end{tabular}

Fonte: Elaborado pelos autores

Se uma estrutura com a mesma massa total $(63 \mathrm{~g})$ fosse feita com barras de aço, cuja densidade é de $7.850 \mathrm{~kg} /$ m3, então o diâmetro destas barras de aço seria de apenas $1,05 \mathrm{~mm}$, caso fosse usada a mesma técnica de construção da geodésica, usando triângulos amarrados. Esta diferença entre os diâmetros dos dois materiais, com a mesma massa, é mostrada na Figura 11, enquanto a barra de aço cobreado tem diâmetro de $1 \mathrm{~mm}$, a barra de bambu tem diâmetro de $3 \mathrm{~mm}$.

Figura 11: Diferentes vistas das barras de bambu e de aço com aproximadamente a mesma massa
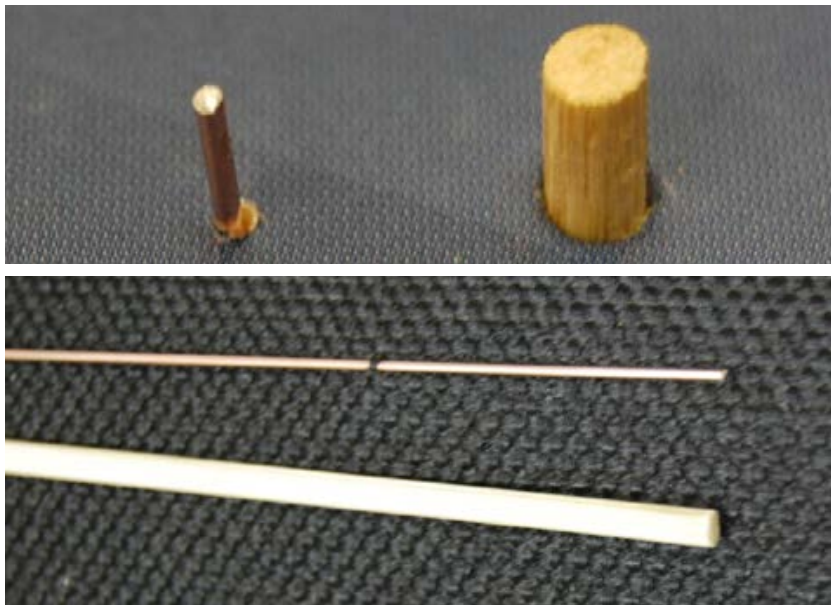

Fonte: Ostapiv

Foi feito então um domo, com as mesmas dimensões do domo de bambu, usando barras de aço carbono cobreado de baixa liga, de diâmetro comercial de $1 \mathrm{~mm}$. As barras foram amarradas, de maneira análoga ao domo de bambu. A massa total da estrutura de aço foi de $56 \mathrm{~g}$, próxima, porém um pouco menor que a massa do domo de bambu, como mostrado na Tabela 03.

Tabela 03: Domo feito com barras de aço carbono de baixa liga de diâmetro $1 \mathrm{~mm}$

\begin{tabular}{|l|c|c|}
\hline Massa média das barras de aço & & $1,3 \mathrm{~g}$ \\
\hline Massa total de aço & & $52,1 \mathrm{~g}$ \\
\hline Massa total da estrutura & & $\mathbf{5 6} \mathbf{g}$ \\
\hline
\end{tabular}

Fonte: Elaborado pelos autores

\section{ENSAIOS DAS MAQUETES DE BAMBU E}

\section{DE AÇO}

Após a construção das maquetes elas foram ensaiadas de modo simples e visualmente didática, usando carregamento hidráulico na estrutura para responder. As estruturas construídas são resistentes?

A estrutura de bambu suportou uma carga de 38 vezes o seu peso, sem romper. Na Figura 12 é mostrada a sequência de carregamento no ensaio da estrutura de bambu.

Figura 12: Carregamento da estrutura geodésica de palitos de bambu mossô com água
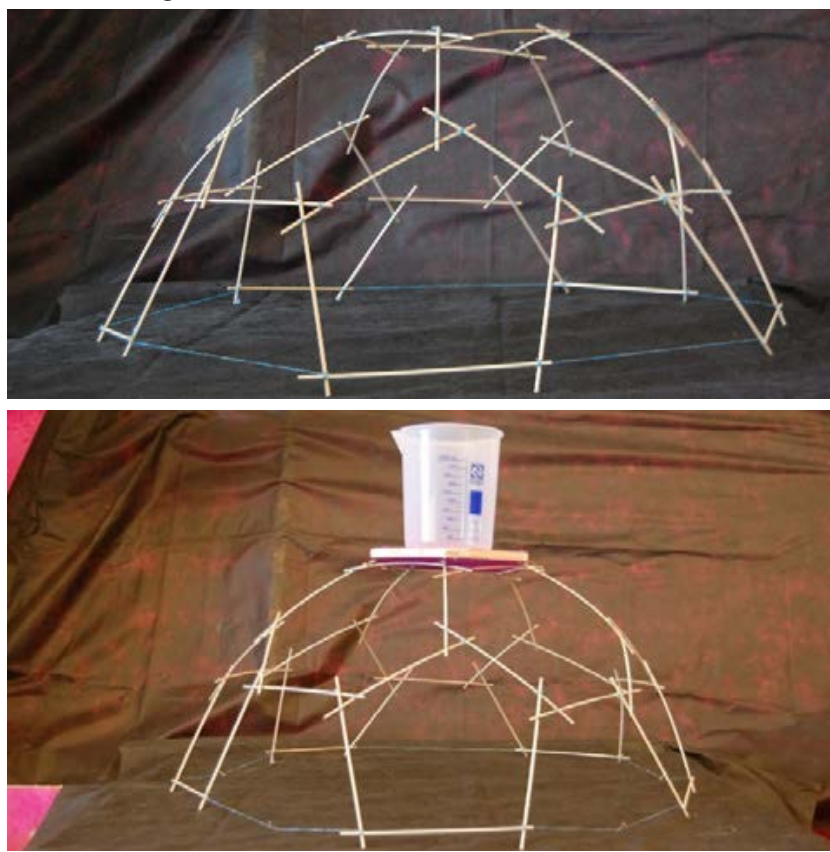

Fonte: Ostapiv

Neste ensaio dos domos, um ponto do topo da estrutura foi marcado como referência. Então mediu-se o deslocamento vertical deste ponto, na medida em que a estrutura era carregada com água. Os resultados são mostrados no Gráfico 01 e 02, mostrando que a estrutura em bambu além de leve, é também muito resistente e flexível. $O$ resultado sugere que, se bem projetado e construído, um domo de bambu poderá resistir o peso de uma caixa d'água. No carregamento final o recipiente continha 1,6 litros de água, como mostrado na Figura 13.

Gráfico 01: Resultados do carregamento hidráulico no domo de bambu

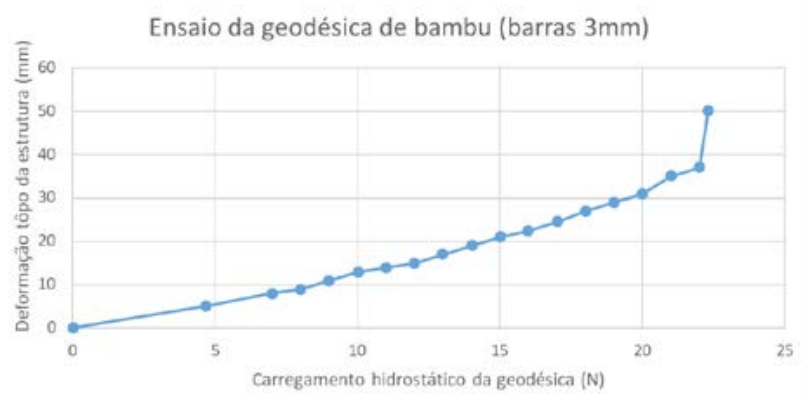

Fonte: Elaborado pelos autores 
No Gráfico 02 é mostrado o comportamento da estrutura geodésica construída em aço com diâmetro de $1 \mathrm{~mm}$ sujeito ao carregamento hidráulico, de maneira análoga ao ensaio da estrutura de bambu. Esta estrutura em aço ficou muito esbelta e com pouca rigidez apresentando grandes deformações com pequenas cargas. A estrutura resistiu apenas $86 \%$ do seu peso próprio e já atingiu a mesma deformação final da estrutura de bambu, mostrando um comportamento mecânico muito inferior.

Figura 13: Recipiente contendo $1600 \mathrm{ml}$ de água sobre a estrutura geodésica de bambu

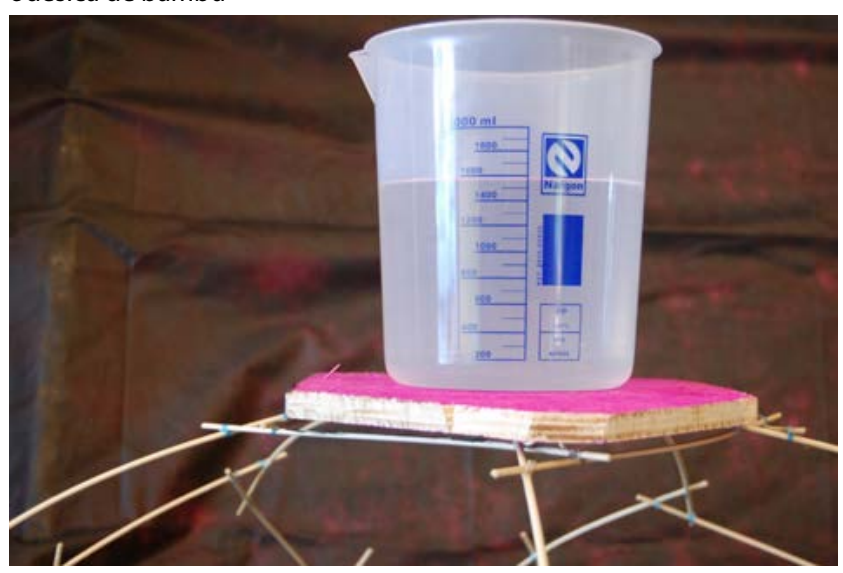

Fonte: Ostapiv

Na Figura 14 é mostrado que a estrutura em aço de $1 \mathrm{~mm}$ de diâmetro entrou em colapso e deformou muito, sem que sequer fosse colocado água no recipiente de 250 $\mathrm{ml}$, pois a estrutura não resistiu ao peso do recipiente, sendo necessário adotar outro método de carregamento. Os resultados são mostrados no Gráfico 03.

Figura 14: Geodésica feita de barras de aço de $1 \mathrm{~mm}$ de diâmetro e colapso da estrutura com recipiente vazio

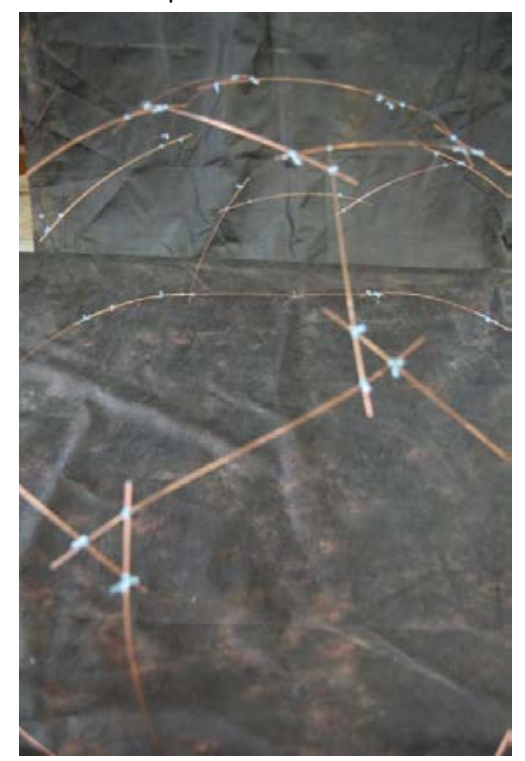

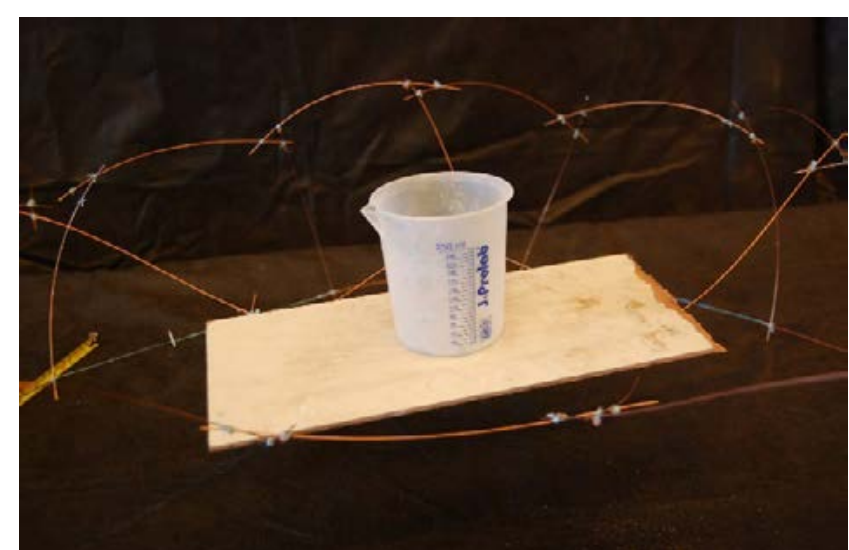

Fonte: Ostapiv

Gráfico 02: Resultados do carregamento hidráulico no domo de aço de baixa liga de diâmetro $1 \mathrm{~mm}$

Ensaio da geodésica de aço (barras $1 \mathrm{~mm}$ )

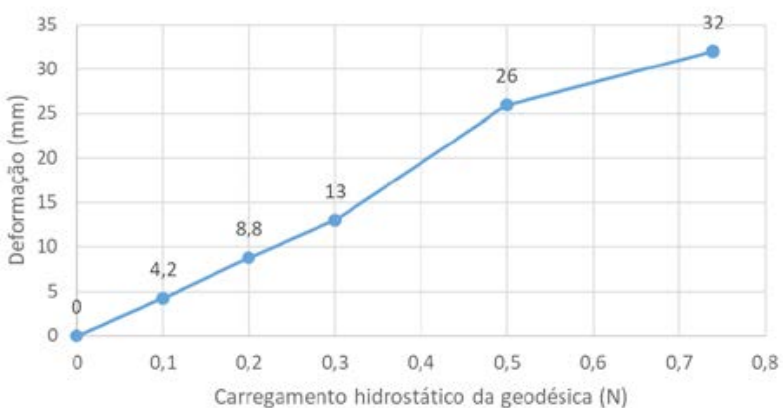

Fonte: Elaborado pelos autores

Os resultados mostram que a estrutura em aço resistiu cargas muito menores para a mesma deformação espacial quando comparada com o domo geodésico feito de bambu, evidenciando que o bambu, assim como as madeiras, é um material que resiste muito carregamento com baixo peso específico.

Por ser um material de origem biológica, e por crescer muito rapidamente, o bambu é um material com baixíssimo conteúdo energético específico $(\mathrm{KJ} / \mathrm{Kg})$, ou seja, ele necessita pouca energia para produzir muita resistência mecânica. Característica esta, de materiais ambientalmente eficientes. Assim, quanto mais o bambu for utilizado na forma de produtos que substituam o uso de materiais mais agressivos ambientalmente, como aço, alumínio e cimento, por terem elevados conteúdos energéticos, melhor para o meio ambiente e para a maioria das pessoas de agora e das gerações futuras de um modo geral.

\section{CONCLUSÕES}

Neste trabalho foram mostrados os passos necessários para a construção de uma estrutura espacial leve, resistente e barata que pode cobrir grandes espaços. $\mathrm{O}$ domo geodésico na forma de um icosaedro rombudo. 
Foram utilizados três materiais diferentes para construção de três estruturas. O domo maior foi feito com colmos de bambu tuldoides, cujo comportamento da estrutura é similar ao domo menor, feito com varetas de bambu mossô.

A técnica construtiva foi discutida passo a passo, na lógica de um manual didático de construção deste tipo de cúpula geodésica usando bambu, o que deve despertar tanto interesse didático como social, podendo ter aplicações na construção civil com baixo custo.

Comprovou-se que a estrutura do domo consegue cobrir grandes espaços usando pouco material e que o uso do bambu para este tipo de construção é muito interessante, permitindo uma boa resistência mecânica para a estrutura.

Neste trabalho ficou evidente que a estrutura geodésica de bambu resistiu um carregamento de 38 vezes o seu peso próprio, apresentando uma deformação de 3,2 $\mathrm{cm}$, ao passo que a estrutura de mesma dimensão e massa, feita de aço, resistiu apenas 0,86 de seu peso para a mesma deformação da estrutura. Ou seja, nestes termos de comparação, a estrutura geodésica em bambu resistiu 44 vezes mais que a estrutura em aço.

\section{REFERÊNCIAS}

BICALHO, J. B. S.; Um estudo sobre poliedros e atividades para o ensino da Matemática: Geometria da bola de futebol e pipa tetraédrica. Dissertação de Mestrado. Universidade Federal de Viçosa, MG, 2013.

CTB - Ciência e Tecnologia da Borracha; Borracha Butílica: Poliisobutileno Isopreno (IIR). https://ctborracha.com/?page_id=4330 Acessado em 10/01/2018.

NASCIMENTO, A. M.; STACHERA, S. F.; XAVIER, L. M.; Determinação de algumas propriedades físicas e mecânicas do Bambusa tuldoides (Munro). In: Congresso lbero-americano de Pesquisa e Desenvolvimento de Produtos Florestais, Curitiba, PR, 2002. 10p.

OSTAPIV, F.; Produção e uso de materiais compósitos bambu-PET na construção civil popular. Capítulo de: Bambus no Brasil, da Biologia à Tecnologia. $1^{\text {a }}$ ed. ICHInstituto Ciência Hoje, pág. 494 a 510, RJ, 2017.

ROZESTRATEN, A. S.; Apuntes acerca del papel de la representación en el processo del proyecto de arquitectura de Paulo Mendes da Rocha. arquiteturarevista - Vol. 5, n²:111-121. São Paulo, 2009.
WANG, Q.H.; HUANG, B.H.; Chinese Moso Bamboo. Zhejiang Science and Technology Publishing House, 1996. 